\title{
Ventilator-associated lung injury: a search for better therapeutic targets
}

\author{
R.A. Oeckler and R.D. Hubmayr
}

ABSTRACT: Acute lung injury (ALI) and acute respiratory distress syndrome (ARDS) represent a continuum of injury that may arise from a number of primary insults.

Localised injury may progress due to trauma from mechanical ventilation, a finding that has led to intense debate in the clinical and experimental literature over optimal ventilator management. The implementation of low tidal volume strategies has led to an improvement in outcomes; however, mortality remains unacceptably high.

In the current review, ventilator-associated lung injury is examined, as it relates to the pathophysiological changes beyond direct airway trauma in ALI and ARDS, and an attempt is made to provide a historical perspective to outline potential current and future pitfalls in the use of surrogate end-points and the discovery of potential biomarkers. The systemic responses that lead to multi-organ dysfunction, the leading causes of morbidity and mortality in ALI and ARDS, are caused by pro-inflammatory signalling cascades and the activation of such diverse mediators as reactive oxygen species, immune response elements, apoptotic constituents and coagulation proteins.

These areas are examined, including key mediators, and possible future areas of interest are discussed, including the potential of an "acute lung injury chip" to integrate measured surrogate biomarkers with real-time clinical information to improve patient outcomes.

KEYWORDS: Acute lung injury, acute respiratory distress syndrome, biomarker, mechanisms, treatment, ventilator-associated lung injury

$\mathbf{T}$ he development and large-scale implementation of mechanical ventilation in the late 1950s and early 1960s was a dramatic step forward in the management of patients with acute respiratory failure. The use of mechanical ventilation in this era drove new insights into respiratory physiology and biomechanics, ultimately leading to the recognition of the acute respiratory distress syndrome (ARDS). Advances in monitoring, imaging and medical informatics have further shaped the evolution of critical care medicine into a specialty with a distinct body of knowledge. The application of evidence-based medicine to critical care has, in turn, confirmed several hypotheses that had originated in physiology and basic science laboratories. The topic of one such hypothesis, ventilator-associated lung injury (VALI), is the focus of the present review article.

For editorial comments see page 1041.
In order to provide an outline of past research and where current and future research is going, a rationale for past, present and future therapeutic end-points will be examined. The paradigm shift from a blood gas tension-driven approach to a mechano-protective one is an informative example of how research has shaped clinical practice. In providing the current review article, the authors hope to take an educated guess at future paradigm shifts.

\section{DEFINITIONS AND HISTORICAL PERSPECTIVE}

ARDS was first described as the adult respiratory distress syndrome by AsHBAUGH et al. [1] in 1967, to differentiate it from immaturity and infant respiratory distress [2]. ARDS was reminiscent of a "shock lung" syndrome with pulmonary oedema and hypoxaemia. It was reported following trauma and sepsis, mostly in surgical patients, from both military and civilian hospitals [3-7]. It

\section{AFFILIATIONS}

Thoracic Disease Research Unit, Division of Pulmonary and Critical Care Medicine, Mayo Clinic,

Rochester, MN, USA.

\section{CORRESPONDENCE}

R.D. Hubmayr

Dept of Pulmonary and Critical Care Medicine

Mayo Clinic

200 First Street SW

Rochester

MN 55905

USA

Fax: 15072844521

E-mail: rhubmayr@mayo.edu

Received:

August 112007

Accepted:

August 162007

STATEMENT OF INTEREST

None declared.
European Respiratory Journal Print ISSN 0903-1936

Online ISSN 1399-3003 
was later determined that ARDS may afflict individuals of all ages, including infants and newborns, and this eventually led to a name change to acute respiratory distress syndrome.

To gain a better understanding of the epidemiology of the syndrome and to stimulate research in ARDS-related disease mechanisms, the American-European Consensus Conference Committee [8] released a statement in 1994 detailing the specific diagnostic criteria detailed in table 1 .

\section{BAROTRAUMA AND VOLUTRAUMA}

Since the initial description of ARDS coincided with the introduction of blood gas analysers into the critical care practice, correction of abnormal arterial blood gas tensions quickly emerged as the primary goal of ventilator management. This led to the appreciation that the application of positive end expiratory pressure (PEEP) and larger than normal tidal volumes $(V \mathrm{~T})$ were effective means of improving pulmonary gas exchange. Moreover, by increasing volume and gas content, PEEP and high tidal ventilation became associated with improved lung radiological appearance, implying clinical benefit. Since the perils of oxygen toxicity had been well established in newborns, treatment strategies to improve oxygenation by mechanical means as opposed to oxygen supplementation were reinforced. Ventilation with large $V \mathrm{~T}$ and airway pressures was often necessary to prevent hypercapnia, whereby it was readily appreciated that normalising gas exchange by mechanical means came at a price, namely a high incidence of barotrauma. Barotrauma, defined as extraalveolar air, was largely attributed to PEEP and found to be a weakening of the lungs' connective tissue network by the intrinsic disease process.

While reports on the detrimental effects of mechanical hyperinflation on the lungs' barrier properties have been found as early as 1963 [9], this problem was not appreciated by the critical care community at the time. In the absence of chest computed tomography, which did not enter clinical practice until the mid 1970s, physicians were not aware of the regional nature of lung injury and labelled ARDS lungs as "stiff", as opposed to functionally small (the baby lung concept [10]). Therefore, the data that ultimately fuelled the paradigm shift in ventilator management away from blood gas-targeted therapy to lung protection were either not yet available or were not appreciated.

By imaging the lungs of patients with ARDS with computed tomography, a series of papers by GATTINONI and co-workers
[10-13] established that injured lungs had heterogenous mechanical properties and that the number of alveoli capable of expanding during a breath was substantially reduced. Accordingly, GATTINONI and co-workers [10-13] considered it more appropriate to think of the ARDS lung as a small baby lung rather than a large stiff lung. As a student, Gattinoni had been exposed to the idea of lung protection and thus recognised that the "baby lung" might be at risk for injury by hyperinflation unless it was "rested". This motivated Gattinoni to examine the efficacy of extracorporeal gas exchange support systems, such as extracorporeal membrane oxygenation (ECMO) [11] and extracorporeal carbon dioxide removal $[12,13]$. ECMO had been tested in the USA in the early $1970 \mathrm{~s}$ as an alternative to conventional mechanical ventilation, but the $90 \%$ mortality outcome was disappointing to say the least [14-16]. The original USA ECMO trial had suffered from serious design flaws (in hindsight, the lungs of ECMO patients had been ventilated at injurious settings), justifying a "second look" by Gattinoni's group and leading to yet another single-centre trial [11]. Unfortunately this second ECMO trial also failed to establish a clinical benefit, and so, at least in the adult population, VALI prevention via ECMO was largely abandoned in the 1990s. Recent anecdotal successes in the cardiovascular surgical arena, however, promise yet another renaissance in ECMO research [17-20].

While the ECMO story was evolving in the mid 1980s, DREYFUSS et al. [21] produced new data reminding the critical care community that mechanical ventilation with large $V$ T was injurious, coining the term "volutrauma". This terminology proved useful as it emphasised that peak lung volume and VT are better surrogates of lung stress than peak airway pressure, plateau airway pressure and airway pressure swings. It also set the stage for influential clinical trials, which ultimately established that mechanical ventilation with $V \mathrm{~T}$ of $12 \mathrm{~mL} \cdot \mathrm{kg}^{-1}$ predicted body weight generated morbidity and mortality in patients with ARDS and acute lung injury (ALI) [22, 23]. These trials did not, however, establish a universally accepted guide to best ventilator practice [24, 25]. There remains controversy about the merits of the open lung strategy, recruitment manoeuvres and best PEEP, and about the relative importance of targeting plateau airway pressure and compliance as opposed to $V$ T to achieve optimal patient outcomes.

These controversies persist because airway pressure, blood gas tensions and regional lung air content are seductive surrogate treatment targets due to their ease of measurement, rapid

TABLE 1 Acute lung injury/acute respiratory distress syndrome (ALI/ARDS) criteria

American-European Consensus Conference Committee diagnostic criteria of ALI/ARDS

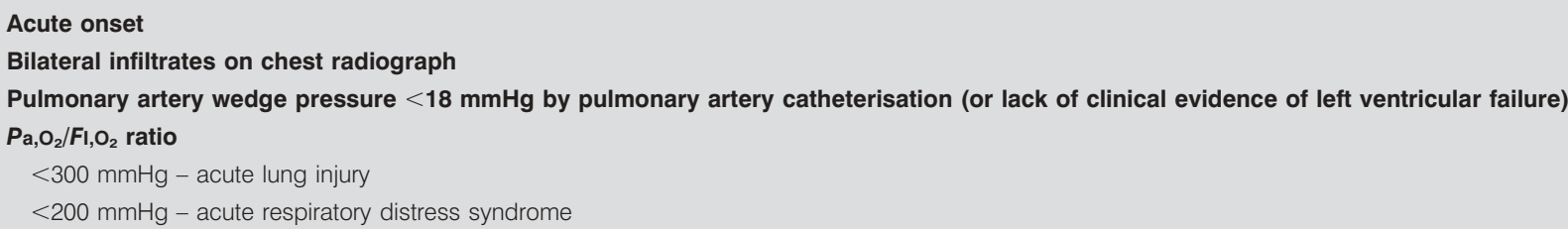

$\mathrm{Pa}_{1} \mathrm{O}_{2}$ : arterial oxygen tension; $\mathrm{Fl}, \mathrm{O}_{2}$ : inspiratory oxygen fraction. $1 \mathrm{mmHg}=0.133 \mathrm{kPa}$. 
response to a change in ventilator settings, and because the physiological determinants of such a response are generally understood. However, these attributes do not validate respiratory system mechanics or gas exchange as surrogates of clinical efficacy, and transient observational time-points may confound conclusions. For example, in the "[Ketoconazole] and Respiratory Management in the treatment of ALI and ARDS" trial [22] patients receiving mechanical ventilation with large $V \mathrm{~T}$ had better oxygenation and a larger respiratory system compliance $24 \mathrm{~h}$ after randomisation than patients randomised to a low $V$ T strategy. Nevertheless, the latter approach was associated with improved survival. Controversies also persist because experimental VALI models tend to be time limited and may not recreate the complex interplay between disease progression and treatment modality that shape lung remodelling and repair responses in patients over days to weeks as opposed to several hours.

\section{BIOTRAUMA}

While the controversies about optimal ventilator management continued throughout the 1990s, work in the field of immunology began to establish important associations between noninfectious environmental stressors and innate immune responses [26-31]. Previously relegated to roles in wound healing and host defence against particulate matter and infectious invaders, the view of the immune system evolved towards that of a multifaceted mechanism acting as a sentry of homeostasis. Immune responses are able to incorporate, interpret and integrate anatomical, physical and chemical input, and it became increasingly clear that they could be modulated by parallel pro- and anti-inflammatory signalling cascades acting on local as well as systemic levels. The paradigm shift came with the understanding that these processes, normally directed towards defence and healing, could themselves be capable of causing tissue injury and disease [32-36].

As research in biochemistry and immunology began to uncover the mechanistic underpinnings of immune responses, it became apparent that many mediators within the networks of bioactive molecules could be influenced or altered by deforming stress. The discovery of mechanosensors in microbes, and the evolving field of mechanotransduction, began to link certain facets of mechanical ventilation with alterations in immunological responses. These underlying processes are fundamental to the notion of VALI, and the associated concept of "biotrauma".

Biotrauma refers to an integrated pro-inflammatory host response to mechanical ventilation. It is the biologist's term for VALI insofar as biotrauma is shaped by mechanical ventilation, but is not singularly caused by it. Biotrauma and VALI are distinct from ventilator induced lung injury (VILI), which describes a deliberate experimental insult to an otherwise normal lung and which therefore is rarely seen in the clinical arena. The importance of biotrauma is emphasised by the loss of pulmonary containment of inflammation in response to deforming stress. This accounts for the high mortality of patients with lung injury and ARDS from multiple organ dysfunction syndrome.

The mediators and biological expressions of biotrauma are varied, involving reactive oxygen species (ROS), cellular growth and apoptotic pathways, coagulation cascades and diverse immune response elements. As such, these mediators and expression systems have become an attractive source of potential biomarkers that complement or supplant more established physiological variables as diagnostic markers, predictors of outcome or surrogates of therapeutic efficacy. In the following sections, the most promising candidate molecules and biotrauma expression systems will be discussed.

\section{NEUTROPHIL RECRUITMENT AND THE IMMUNE RESPONSE}

Neutrophil (polymorphonuclear leukocyte, PMN) recruitment is an important regulator of inflammation associated with ALI and ARDS. In the initial stages of ALI and VILI, there are very few extravascular PMNs, and it is during this stage that the release of cytokines and chemokines, largely derived from epithelial cells and alveolar macrophages, promotes the adhesion, aggregation and diapedesis of PMNs into the lung interstitium. It is at this point that clinical and physiological manifestations of lung injury become first apparent. It is not surprising then, that the resolution of neutropenia is temporally associated with worsening lung function in neutropenic hosts [37]. Reports of ALI in neutropenic patients [38] merely emphasise the complexity and redundancy of disease mechanisms associated with lung injury.

For a PMN to traverse the small pulmonary capillaries, it must undergo a considerable change in shape to squeeze through the convoluted architecture of the microcirculation. This leads to increased transit times, creating a "physiological sink" of PMNs within the lung, even under normal conditions [39]. Therefore, a large pool of PMNs exists locally, and is available at all times for recruitment if the proper triggers manifest themselves. This anatomical and physical constraint is distinct from the well-described immune processes of migration, rolling and adhesion that occur in inflammatory states, such as ALI. The former is a result of inalterable anatomical and physical properties, while the latter is a dynamic process under the direction of cytokines, chemokines and chemoattractants.

Animal models confirm that PMN recruitment occurs early in ALI [39-41], and that it is mediated by immune mechanisms. Injurious ventilation in mice causes PMN sequestration within the lungs at a stage before alterations in mechanics and gas exchange are detectable. In VILI models, sequestration was independent of CD18 antibody, an inflammatory mediator of leukocyte-endothelial cell interactions well characterised in the response to lipopolysaccharide (LPS) [42]. The repeated collapse and cyclic overdistension of alveoli associated with high tidal ventilation is associated with the activation of key inflammatory cascades. Studies in the perfused rabbit lung [43] demonstrated that mechanical ventilation with fixed levels of PEEP resulted in activation of nuclear factor $(\mathrm{NF})-\kappa \mathrm{B}$, activator protein- 1 and the cAMP-responsive element binding protein, all potent inducers of downstream chemokine and cytokine release. However, when PEEP was continually adjusted to maintain full endexpiratory alveolar recruitment, less activation of these early inflammatory signalling cascades was found. Similar findings were recently reported in humans [44-47].

Cyclical collapse and overdistension of alveoli has also been associated with a local change in endothelial permeability 
(a hallmark of both ALI and sepsis) and surfactant production with consequent development of pulmonary oedema. The process is compounded by the deposition of fibrin and a shift towards a pro-coagulant state, a state that promotes hypoxia and fibroproliferation [5]. Hypoxia can inhibit apoptosis of quiescent PMNs, enhances the cytotoxic function of PMNs [48], and may therefore lie at the centre of a positive feedback loop perpetuating injury. It would seem then that the PMN or its regulatory pathways should be rife with measurable markers and targets for diagnostics, prognostics and immuno- or pharmacotherapy. Unfortunately, the plasticity of immunoregulatory networks that shape temporally and spatially distinct manifestations of biotrauma remains poorly understood. As a result, most ARDS biomarker studies have focused on a very small number of molecules. Post hoc analyses suggest that ventilator management decisions, which were subsequently identified as harmful, were associated with increased levels of cytokines and chemokines in circulation and bronchoalveolar lavage fluid (BAL) [49-51]. However, to date, the utility of these molecules in guiding management decisions has not been established. Uncertainty about their cellular origin, kinetics and their specific roles in shaping injury and repair responses are some of the more apparent barriers to such an undertaking.

The most promising molecular candidates are likely to be at the hubs of intersecting pathways and thereby affect more than one molecular species. For example, increased levels of the regulatory peptide adrenomedullin (ADM) are present in patients with systemic inflammatory response. Studies in both human and pig cell monolayers have demonstrated an ADMmediated barrier protective effect involving not one, but three different effector mechanisms, as follows: ROS, thrombin and Escherichia coli haemolysin-mediated inflammatory pathways [52]. Importantly, the same study demonstrated that pharmacological pre-treatment with ADM blocked oedema formation in isolated perfused rabbit lungs. The well known anti-inflammatory and immunosuppressive agent propofol has also been effective in pre-clinical studies [53]. Rabbits exposed to a rather high dose of propofol $\left(15 \mathrm{mg} \cdot \mathrm{kg}^{-1}\right)$ prior to endotoxin exposure demonstrated less PMN sequestration, and decreased capillary permeability and pulmonary oedema. There does not appear to be a class effect, as two increasingly common anti-inflammatory and immunosuppressant compounds have been implicated in the development of ALI. Sirolimus [54], an anti-inflammatory and anti-proliferative agent used most commonly in cardiac stents, and rituximab [55], the anti-CD20 chemotherapy agent, have both been associated with ALI.

A detailed description of biomarkers of ALI is beyond the scope of the present review; however, in order to provide a flavour of the depth and diversity of this area of research, a brief summary follows. High mobility group box 1, a transcriptional regulator protein, previously implicated in late endotoxin lethality, appears to be involved in toxic and environmental chemical-induced ALI [56]. Toll-like receptor 4 signalling appears to regulate pro-inflammatory cytokines, such as NF- $\kappa$ B, interleukin (IL)- $1 \beta$ and -6 , induced by LPS in mice [57]. The antioxidant flavonoid hesperidin has immunomodulatory properties, and in a murine model of LPS-induced ARDS, successfully inhibited the expression of a number of pro-inflammatory mediators, including IL-8, tumour necrosis factor $(\mathrm{TNF})-\alpha$, IL-1 $\beta$, IL-6, IL-12, intercellular adhesion molecule-1 and vascular cellular adhesion molecule-1 [58]. Serum levels of heat shock protein (Hsp)60 correlate with the development of ALI and are thought to reflect cell necrosis. Hsp60 acts on immunocompetent cells to cause the release of cytokines and nitric oxide, triggering a strong inflammatory response within the lung [59]. Finally, the complementary system is the mediator of the body's humoral immunity, and nearly half of its proteins are involved in regulation of the pathway. Therefore, it is no wonder that the complementary system remains an important area of current pharmaceutical investigation, even though no probes of proteins involved in pathway regulation are currently commercially available [60].

ALI often complicates sepsis and could be considered a consequence of the associated cytokine storm [61]. Haemodialysis is effective in removing mediators, such as IL-6, IL-8 and TNF- $\alpha$ [62-68]; however, to date, no study of either haemodialysis or plasmapheresis has specifically targeted ALI patients. Targeting of multiple agents would be of interest because, as discussed previously, it is unlikely that the modulation of any one mediator or pathway will be successful in achieving better outcomes.

\section{COAGULATION}

Many studies [69-76] have established mechanistic interactions between the coagulation cascade and the immune system. The recent literature on sepsis [77-82] speculates about improved outcomes in patients receiving anticoagulant therapy, regardless of whether it is in the form of heparin, activated protein C, hirudin or leperudin. For example, mice with naturally reduced factor VII production have an attenuated inflammatory response and enhanced survival when exposed to endotoxin [83]. Primates with sepsis-induced ALI that have received therapy targeted at the intrinsic pathway demonstrated protection from fibrin deposition, decreased markers of inflammation and improved lung function [81].

Animal models further implicate abnormalities of fibrin turnover in the pathogenesis of acute inflammation and fibrotic repair [69-71, 84-87]. As discussed earlier, the process of fibrin deposition may be a means for the lung to localise or "wall off" inflammation, thereby limiting the risk of dissemination to neighbouring lung regions and the systemic circulation [69]. Human alveolar epithelial type II (AT2) cells and immortalised alveolar epithelial type I cells (A549) have the ability to modulate protein C [69] and tissue factor expression [87], and therefore are capable, along with PMNs, of influencing pro- and anticoagulant activities within the alveolar space.

Several groups have examined the regulation of matrix turnover and the diagnostic and prognostic significance of coagulation factors in patients and experimental models of ALI [74, 88-90]. Of these, a promising clinical marker is the plasminogen activator inhibitor. In human studies, levels of plasminogen activator inhibitor-1 were significantly higher in ALI when compared with patients with hydrostatic oedema, and the test identified those with ALI with a high sensitivity and specificity [74].

\section{REACTIVE OXYGEN SPECIES}

Deforming stress promotes the generation of ROS, and ROS signalling is likely to play an important role in the pathogenesis 
of hyperinflation injury. Unfortunately, many of the techniques used to measure these unstable compounds cannot be employed at the bedside. As such, questions of specificity, toxicity and potential autogeneration of ROS by both detection agents, including dihydroethidium, dichlorofluorescein and lucigenin [91], and molecular probes have come into question. In addition, variations in cell permeability, compartmentalisation, autoreactivity and the presence of ROS scavenging systems (nitric oxide, superoxide dismutase, catalase, glutathione, thiols) and chelating agents $\left(\mathrm{Ca}^{2+}, \mathrm{Cu}\right.$, EDTA, EGTA) all add complexities that may explain conflicting results in the literature [92].

An example is nitric oxide, a molecule likened to a doubleedged sword based on observations in both experimental animal models and human clinical trials. One explanation for this likeness may be dose- or species-specific responses to nitric oxide. In a murine ALI model, overexpression of endothelial nitric oxide synthase was associated with a reduction in lung injury [93], yet the opposite was observed in rats [94]. Here microvascular leakage was used as a surrogate of ALI, and rats ventilated with high $V \mathrm{~T}$ $\left(20 \mathrm{~mL} \cdot \mathrm{kg}^{-1}\right)$ had an upregulation of endothelial nitric oxide synthase that correlated directly with microvascular leakage in an $N^{\mathrm{G}}$-nitro-L-arginine methyl ester-dependent fashion.

Clinical trials taking place as early as 1993 indicated that inhaled nitric oxide could improve oxygenation in ALI [95], and concerns about toxicity drove studies to optimise delivery of the gas to the part-per-billion range $[96,97]$. At these low concentrations, nitric oxide was found to improve arterial oxygen tension in most patients independent of pulmonary vascular resistance [98] and appears to be protective of the pulmonary vascular endothelium [98]. At higher concentrations, however, nitric oxide scavenging by ROS begins to yield reactive nitrogen species and other intermediates, such as peroxynitrite, that are capable of altering cellular respiration, enhancing ROS production, lipid peroxidation, endothelial injury and loss of barrier function [98, 99].

The mechanism of ROS-mediated increases in endothelial permeability remains unclear, and even the sources of ROS within the lung under physiological and pathological conditions remain controversial. The mitochondria, xanthine oxidase and $\mathrm{NAD}(\mathrm{P}) \mathrm{H}$ oxidase have all been implicated as important sources for stretch-dependent endogenous production of superoxide. In rat AT2 cells and immortalised human airway epithelial cells (A549), cyclic mechanical strain increases ROS production in a dose-dependent manner once a critical threshold is reached [100], and the same has been seen in bovine pulmonary arteries [101]. A number of targets for ROS-induced permeability changes have been suggested, and include vascular endothelial growth factor (VEGF), endothelial growth factor and subsets of the mitogen-activated protein kinase cascades [102], yet the actual effector mechanisms downstream remain elusive.

Pharmacological interventions in animal models of ALI aimed at modulating ROS levels have been met with mixed results. For example, the $\mathrm{NAD}(\mathrm{P}) \mathrm{H}$ oxidase inhibitor apocynin attenuated sepsis-induced lung injury, as well as neutrophil ROS generation in both guinea pigs and human umbilical vein endothelial cells [103], and polyethylene glycol-conjugated superoxide dismutase attenuated lung injury in E. coli-treated guinea pigs [104]. In a mouse model of ALI, administration of $N$-acetylcysteine $1 \mathrm{~h}$ after endotoxin challenge prevented the impairment of hypoxic pulmonary vasoconstriction and attenuated sepsis-associated ALI [105]. The administration of methylprednisone in isolated perfused rat lungs attenuated ROS-induced vasoconstriction and bronchoconstriction [106].

There have been few clinical trials targeting ROS generation, and none suggesting benefit. Issues include toxicity and efficacy, and neither of the probes can be used in humans; in addition, as in the case of $\mathrm{N}$-acetylcysteine or nitric oxide, the results of encouraging pre-clinical trials could not be reproduced in the clinical arena. This reinforces the notion that a single component in an integrated system is rarely the lynchpin of a complex mechanism. An alternative approach may be to compile datasets of key markers to either prognosticate or track disease development and progression [107].

\section{APOPTOSIS}

The fundamental question about the role of apoptosis in the pathogenesis of VALI is whether the process is good or bad. The answer is clear: "it depends". Context is important in many mechanisms of ALI, but it would seem none are more important than in apoptosis. Apoptosis is a sine qua non of tissue remodelling and repair. To use the somewhat antiquated metaphor of apoptosis as "programmed cell death," one can easily appreciate the wisdom of terminating the exudative phase of inflammation by "programming" the destruction of PMNs or alveolar macrophages, for example, after invading pathogens have been removed. Conversely, the unintended programming of the destruction of alveolar epithelial cells would create alveolar wounds and could trigger fibroproliferation. It is therefore not surprising that the investigation of molecular targets deemed to be important pro- or antiapoptotic regulators continues in earnest. An example is TNF- $\alpha$, a pro-inflammatory cytokine whose levels are consistently elevated in the BAL fluid of ALI patients. It has been shown to have a biphasic effect on the rate of PMN apoptosis, with long-term suppression being mediated through the antiapoptotic chemokine IL-8 [108]. Furthermore, TNF- $\alpha$ has been implicated in endothelial cell apoptosis and consequent barrier dysfunction, leading to hyperpermeability [109]. Initially, the molecule was thought to be a key inciting factor for oedema formation, but it now appears that the initial phase of lung injury is independent of TNF- $\alpha$, macrophage-inflammatory protein-2 or IL-6 [110], even though there is an association between barrier dysfunction and apoptosis [111].

Beyond apoptosis, TNF- $\alpha$ has been shown to attenuate multiple ALI-related processes, from the activated protein C-mediated intra-alveolar fibrin deposition by alveolar epithelial cells [69] to the induction of intercellular adhesion molecule-1 surface expression [112]. The latter entails mechanisms dependent on protein kinase $\mathrm{C}$ and intracellular ROS, re-emphasising the complexity and redundancy of the systems involved in the pathogenesis of ALI. To this complexity must be added the further nuances of timing, cell (or tissue) type, and the concurrent conditions of the local milieu. This added contextual layer alters the roles of certain key mediators, influencing their interactions depending on the pre-set condition. 
The biological effects of TNF- $\alpha$ have been emphasised for the sake of a representative example; similar observations have been made concerning NF- $\kappa \mathrm{B}$, proteinase activated receptor-1, peroxisome proliferator-activated receptor- $\gamma$ and haem oxygenase. All have been shown experimentally to influence apoptosis rates, but none have had an effect on survival in animal models [113-120]. Parallel work in human alveolar macrophages further delineates the context of environmental conditions. Targeting specific mediators did not affect spontaneous apoptosis rates under physiological conditions, yet in LPS-induced apoptosis, the macrophage-activating cytokine interferon- $\gamma$ enhanced apoptosis, while macrophage-deactivating cytokines IL-4, IL-10 and transforming growth factor- $\beta$ became anti-apoptotic mediators [121].

Again, the question of a useful ALI biomarker arises. Have the advances in apoptosis-related assays reached a level that might provide a potentially inexpensive, noninvasive diagnostic and prognostic marker? Two such molecules of interest are granulocyte-macrophage colony-stimulating factor (GM-CSF) and VEGF. GM-CSF has been shown to suppress apoptosis in normal neutrophils incubated in the plasma of patients with ALI, and exploitation of this process by the administration of GM-CSF receptor antibody has been suggested as a novel treatment modality [122]. In addition, there may be prognostic value, as GM-CSF in BAL fluid correlated directly with patient survival; those with significantly higher levels were more likely to survive [123].

The VEGF receptor, implicated in multiple models of proliferative and apoptotic pathways, has been linked to increased vascular permeability in ARDS. In human ARDS patients a decrease in VEGF from intensive care unit day 1 to day 4 was associated with improved outcomes and reduction in overall mortality to $12 \%$, while an increase in VEGF over the same time period predicted $78 \%$ mortality. Those with more than a doubling of VEGF levels had 100\% mortality [124].

\section{CELL WOUNDING AND REPAIR}

The term injury has been used to describe biological responses as diverse as altered gene or protein expressions, abnormal respiratory mechanics, inefficient gas exchange, impaired vascular barrier properties or the remodelling of lung structures. Therapies directed against each and every one of these injury manifestations exist, but to date none of them has influenced ARDS survival. So far, the only effective therapy is low VT mechanical ventilation, maybe because it is directed at the stimulus, deforming stress, as opposed to single elements of a complex immune response to that stimulus. Demands for pulmonary gas exchange set limits by how much the deforming stress associated with breathing may be reduced. While the critical care community has for the most part accepted hypercapnic acidosis as a sometimes necessary consequence of lung protective mechanical ventilation, the demand for oxygen uptake still requires that some minimal alveolar ventilation be achieved [125]. Therefore, pharmacoprotective interventions, which prevent the deleterious consequences of lung deformation and which modify cellular mechano-transduction, defined in its broadest terms, would be of great value as adjuncts to lung protective mechanical ventilation.
Adherent lung parenchymal cells, which are exposed to mechanical ventilation with high volumes and transpulmonary pressure, experience reversible plasma membrane wounds [126-128] and, as a result, initiate pro-inflammatory signalling cascades [129]. Cells possess a vast repertoire of genomic and physiomic responses to deforming stress, most of which occur in the absence of structural lesions [130]; however, the evidence for the existence of wounded lung cells in patients with VALI and in experimental models of VILI is compelling [126, 127] and therefore the hypothesis that wounded lung cells are important transducers of injurious stress is attractive. It follows that interventions that reduce the susceptibility of lung cells to stress failure may be just as effective in preventing VALI as the reduction of the injurious stimulus itself, namely low $V \mathrm{~T}$, has turned out to be. Raising blood tonicity with hypertonic saline or mannitol solutions could potentially achieve this goal because of the following reasons. 1) Hypertonic exposure reduces cell volume and thereby creates a relative excess of plasma membrane. As a result, the lipid bilayer of the plasma membrane can simply unfold with a minimal increase in lateral tension when an externally imposed cell shape change demands it. 2) Hypertonic exposure reduces the water activity inside the cell and promotes a state of increased cytoskeleton polymerisation, which has the following consequences. 1) Stress tolerance of the subcortical cytoskeleton, i.e. the critical stress at which the cytoskeleton network yields or brakes, is increased; 2) the lipid bilayer of the plasma membrane, which coats the subcortical cytoskeleton, is less likely to experience lytic tension; 3) plasma membrane wounds that do develop are smaller and are therefore more likely to heal; 4) translocation of nucleation factors to the submembranous actin cytoskeleton accelerate cytoskeleton remodelling and repair (the latter may be triggered by a calcium-induced phase transition (displacement of ordered water molecules by $\left(\mathrm{a}^{2+}\right.$ ) at the wound); and 5) a more tightly woven actin network at the wound base would serve as the matrix for wound closure by lateral plasma membrane lipid flow.

While these hypotheses have strong cellular biological support, they have not been sufficiently tested in pre-clinical VALI models, let alone in patients. Moreover, the clinical experience of using hypertonic solutions, for example, in brain injury and trauma victims, does not consider the safety of maintaining an increased plasma osmotic pressure for extended periods of time.

Many of the epithelial, endothelial and inflammatory cellderived biomarkers studied to date may be considered surrogates of cell wounding. However, in aggregate they are no more specific than physiological and clinical characteristics embedded in prognostic systems, such as the Simplified Acute Physiology Score and Acute Physiology and Chronic Health Evaluation, so that their roles as monitors of disease severity or treatment effect remain to be established. For this reason, avoidance of potentially harmful lung-distending pressure and maybe monitoring of regional aeration are currently more effective therapeutic guides than serial measures of protein and lipid mediators in plasma or BAL. 


\section{FUTURE DIRECTIONS}

The critical care community would like to see biomarkers inform about lung inflammation in the same way that troponin informs about myocardial injury. The ALI mediators studied to date do in fact achieve this. However, there are several reasons why, at least in the near future, their clinical utility will not rival that of cardiac biomarkers. The lung is a more complex organ and the questions posed by critical illness syndromes that involve the lungs are more nuanced and challenging. The recognition of ALI as a complex, holosystemic response is likely to drive the next paradigm shift and shape future research. That shift may already be underway, as a multidisciplinary approach spurred by network- and systems-based theory begins to take hold, encouraging the integration of the traditional fields of basic science with advances in computer modelling, analysis and bioinformatics. Tangible examples include the raw computational power harvested to decode and map the human genome, and the related subsequent advance in gene and proteomic microarrays (gene or protein "chips"). These techniques currently enable and drive the analyses of thousands of DNA or RNA sequences and their associated molecules, proteins and signalling cascades, unlocking advanced interrelationships previously not envisioned, although not for lack of imagination, but for lack of computing power to handle signalling networks on a scale too vast for conventional techniques to grasp.

The true power not only comes from the adept acquisition and analysis of large amounts of data, but also from the ability to store and quickly retrieve this information for comparative purposes. For example, a patient could be admitted to an intensive care unit of the future where a clinical and physiological assessment takes place (fig. 1). A laboratory sample would be taken and submitted for microarray analyses, using an acute lung injury chip. The patient's unique "chip fingerprint" could then be compared with a database of previously collected (and continuously growing) profiles of acute lung injury patients for optimisation of interventions, prognostic value and perhaps even monitoring on a real-time, or quasi-real-time basis. The advantages are clear and wideranging. Not only does the individual patient benefit from the stored pool of knowledge, but so too does the collective knowledge base with each new case. While genomics and proteomic networks have captured the imagination of physicians, scientists and futurists, their integration with physiomics and syndromics will truly revolutionise critical care medicine. As the present knowledge expands, the use of datasets and the ability to tag groups of pathways involved in specific processes with keywords, such as "diabetes" or "acute lung injury", will allow healthcare providers to abstract and comprehend large volumes of data. The power of Boolean searching and tagging via signalling or mediator connections (similar to an internet search engine, such as Google) should allow not only for an easier, but also for a more intuitive way to understand these complex associations, and open up therapeutic targeting or treatments in previously unimaginable ways. Given the incredible complexity and redundancy in disease mechanisms, it would be a cliché to emphasise the difficulty of "seeing the wood for the trees". Whether that refers to the mosaic patterns of thousands of mediators on a theoretical acute lung injury chip, or to contextual layers in combination with, or on top of, networking systems and signalling cascades, the differentiation between the full forest and the rest of the trees can sometimes be problematic. With regard to novel treatment modalities for acute lung injury and acute respiratory distress syndrome, the controversial questions may soon ask where one should stand in order to optimise the view.

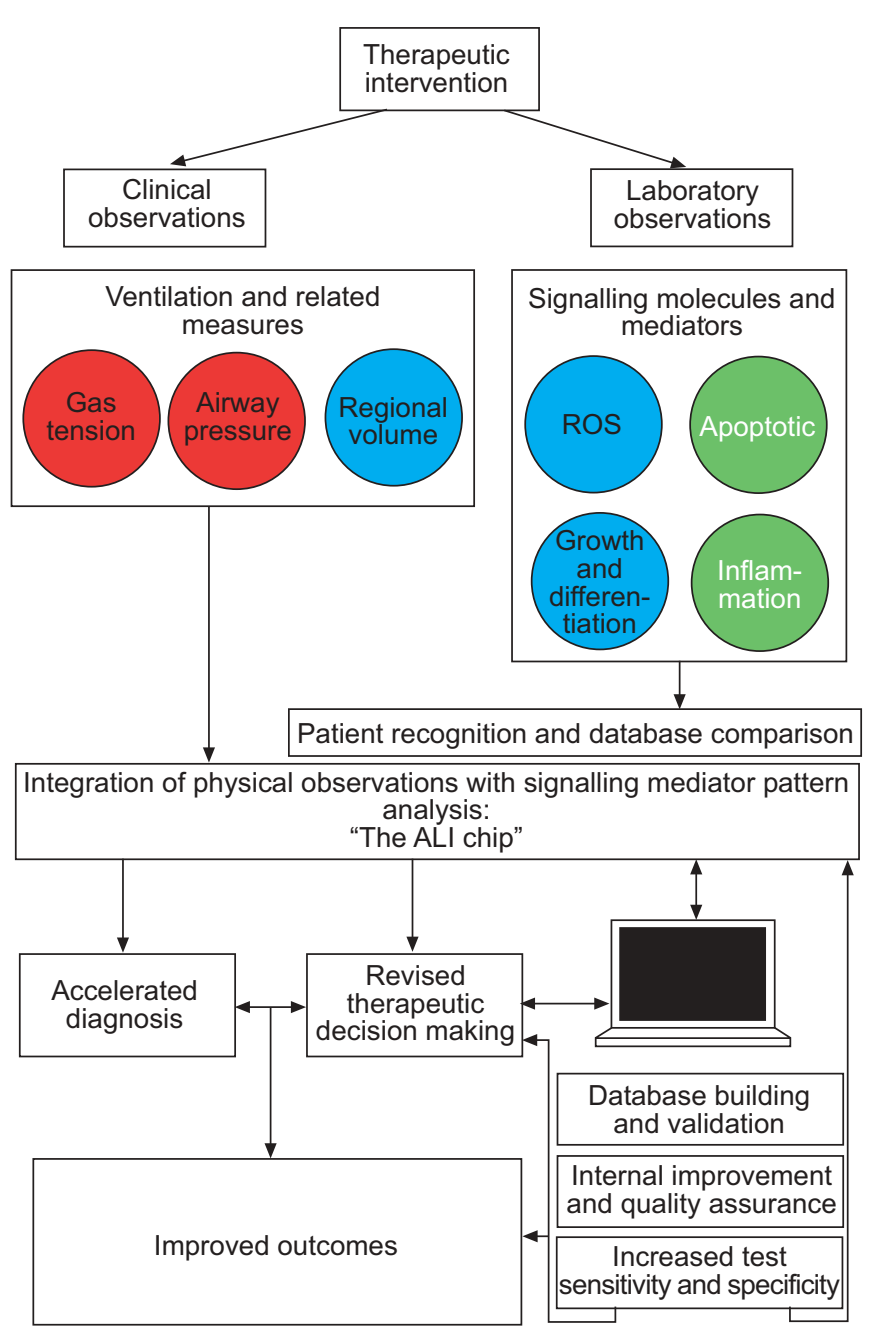

FIGURE 1. The "acute lung injury (ALI) chip". A proposed mechanism for the analytical integration of clinical observations with laboratory data obtained in patients with ALI. Examples of potential future data points include reactive oxygen species (ROS), and mediator levels from a number of pathways involved in the pathophysiology of ALI (see text for details). Microarray technology can search for abnormal levels or patterns of change in important mediators, and further contextualise the results through the integration of clinical data, such as that from haemodynamic and ventilator monitoring. Advances in computing power, artificial intelligence and network system theory aid in raw and comparative analysis to benefit the current patient by immediate retrieval of similar cases, treatment strategies and outcomes, to providing immediate feedback, as well as the potential for suggesting interventions with a reported statistical basis for success. Finally, the system is dynamic, "learning" by the addition and integration of each new case into its repertoire of databases, to improve predictive ability and outcomes over time. The utility level based on current evidence is as follows: green: promising; blue: uncertain; red: unlikely. 


\section{REFERENCES}

1 Ashbaugh DG, Bigelow DB, Petty TL, Levine BE. Acute respiratory distress in adults. Lancet 1967; 2: 319-323.

2 Masi A, Belisario C, Vecchi C. The respiratory distress syndrome (RDS) in the premature infant. Riv Clin Pediatr 1965; 76: 260-285.

3 McLaughlin JS, Suddhimondala C, Mech KF, et al. Pulmonary function in human shock. Surg Forum 1968; 19: 43-46.

4 Lucas CE, Ross M, Wilson RF. Physiologic shunting in the lungs in shock or trauma. Surg Forum 1968; 19: 35-37.

5 Harrison LH Jr, Beller JJ, Gill CC, Hinshaw LB, Coalson JJ, Greenfield LJ. Effects of endotoxin on pulmonary capillary permeability and surfactant. Surg Forum 1968; 19: 250-251.

6 Keller CA, Schramel RJ, Hyman AL, Creech O Jr. The cause of acute congestive lesions of the lung. J Thorac Cardiovasc Surg 1967; 53: 743-753.

7 Cahill JM, Jouasset-Strieder D, Byrne JJ. Lung function in shock. Am J Surg 1965; 110: 324-329.

8 Bernard GR, Artigas A, Brigham KL, et al. The AmericanEuropean Consensus Conference on ARDS. Definitions, mechanisms, relevant outcomes, and clinical trial coordination. Am J Respir Crit Care Med 1994; 149: 818-824.

9 Greenfield LJ, Ebert PA, Benson DW. Atelectasis and surface tension properties of lung extracts following positive pressure ventilation and overinflation. Surg Forum 1963; 14: 239-240.

10 Gattinoni L, Pesenti A. The concept of "baby lung". Intensive Care Med 2005; 31: 776-784.

11 Gattinoni L, Pesenti A, Bombino M, Pelosi P, Brazzi L. Role of extracorporeal circulation in adult respiratory distress syndrome management. New Horiz 1993; 1: 603-612.

12 Gattinoni L, Pesenti A, Mascheroni D, et al. Lowfrequency positive-pressure ventilation with extracorporeal $\mathrm{CO}_{2}$ removal in severe acute respiratory failure. JAMA 1986; 256: 881-886.

13 Gattinoni L, Agostoni A, Pesenti A, et al. Treatment of acute respiratory failure with low-frequency positivepressure ventilation and extracorporeal removal of $\mathrm{CO}_{2}$. Lancet 1980; 2: 292-294.

14 Zapol WM, Snider MT, Hill JD, et al. Extracorporeal membrane oxygenation in severe acute respiratory failure. A randomized prospective study. JAMA 1979; 242 2193-2196.

15 Browdie DA, Deane $\mathrm{R}$, Shinozaki $\mathrm{T}$, et al. Adult respiratory distress syndrome (ARDS), sepsis, and extracorporeal membrane oxygenation (ECMO). J Trauma 1977; 17: 579-586.

16 Gille JP, Bagniewski AM. Ten years of use of extracorporeal membrane oxygenation (ECMO) in the treatment of acute respiratory insufficiency (ARI). Trans Am Soc Artif Intern Organs 1976; 22: 102-109.

17 Thourani VH, Kirshbom PM, Kanter KR, et al. Venoarterial extracorporeal membrane oxygenation (VA-ECMO) in pediatric cardiac support. Ann Thorac Surg 2006; 82: 138-144; discussion 144-135.

18 Totapally BR, Sussmane JB, Torbati D, et al. Cardiovascular stability during arteriovenous extracorporeal therapy: a randomized controlled study in lambs with acute lung injury. Crit Care 2004; 8: R495-R503.

19 Santiago A, Ramos I, Quintana C. Extracorporeal membrane oxygenation: successful bridge to pediatric heart transplantation. P R Health Sci J 2004; 23: 59-63.

20 Gold JP, Torres KE, Maldarelli W, Zhuravlev I, Condit D, Wasnick J. Improving outcomes in coronary surgery: the impact of echo-directed aortic cannulation and perioperative hemodynamic management in 500 patients. Ann Thorac Surg 2004; 78: 1579-1585.

21 Dreyfuss D, Soler P, Basset G, Saumon G. High inflation pressure pulmonary edema. Respective effects of high airway pressure, high tidal volume, and positive endexpiratory pressure. Am Rev Respir Dis 1988; 137: 1159-1164.

22 The Acute Respiratory Distress Syndrome Network. Ventilation with lower tidal volumes as compared with traditional tidal volumes for acute lung injury and the acute respiratory distress syndrome. The Acute Respiratory Distress Syndrome Network. N Engl J Med 2000; 342: 1301-1308.

23 Petrucci N, Iacovelli W. Ventilation with lower tidal volumes versus traditional tidal volumes in adults for acute lung injury and acute respiratory distress syndrome. Cochrane Database Syst Rev 2003; CD003844.

24 Artigas A, Bernard GR, Carlet J, et al. The AmericanEuropean Consensus Conference on ARDS, part 2: ventilatory, pharmacologic, supportive therapy, study design strategies, and issues related to recovery and remodeling. Acute respiratory distress syndrome. Am J Respir Crit Care Med 1998; 157: 1332-1347.

25 Dreyfuss D, Saumon G. Evidence-based medicine or fuzzy logic: what is best for ARDS management? Intensive Care Med 2002; 28: 230-234.

26 Zaas AK, Schwartz DA. Innate immunity and the lung: defense at the interface between host and environment. Trends Cardiovasc Med 2005; 15: 195-202.

27 Vercelli D. Innate immunity: sensing the environment and regulating the regulators. Curr Opin Allergy Clin Immunol 2003; 3: 343-346.

28 Lambrecht BN, Prins JB, Hoogsteden HC. Lung dendritic cells and host immunity to infection. Eur Respir J 2001; 18 : 692-704.

29 Zhang P, Summer WR, Bagby GJ, Nelson S. Innate immunity and pulmonary host defense. Immunol Rev 2000; 173: 39-51.

30 Diamond G, Legarda D, Ryan LK. The innate immune response of the respiratory epithelium. Immunol Rev 2000; 173: 27-38.

31 Mannie MD. Immunological self/nonself discrimination: integration of self $v$ s nonself during cognate $\mathrm{T}$ cell interactions with antigen-presenting cells. Immunol Res 1999; 19: 65-87.

32 Oldstone MB. Molecular mimicry and immune-mediated diseases. FASEB J 1998; 12: 1255-1265.

33 Putterman C, Limpanasithikul W, Edelman M, Diamond B. The double edged sword of the immune response: mutational analysis of a murine anti-pneumococcal, antiDNA antibody. J Clin Invest 1996; 97: 2251-2259.

34 Clynes R, Ravetch JV. Cytotoxic antibodies trigger inflammation through Fc receptors. Immunity 1995; 3: 21-26. 
35 Sprent J, Kosaka H. T cell tolerance and self/nonself discrimination. Autoimmunity 1993; 15: 155-161.

36 Hines WH, Haverty TP, Elias JA, Neilson EG, Kelly CJ. T cell recognition of epithelial self. Autoimmunity 1989; 5: 37-47.

37 Azoulay E, Darmon M, Delclaux C, et al. Deterioration of previous acute lung injury during neutropenia recovery. Crit Care Med 2002; 30: 781-786.

38 Abraham E. Neutrophils and acute lung injury. Crit Care Med 2003; 31: Suppl. 4, S195-S199.

39 Doerschuk CM, Allard MF, Martin BA, MacKenzie A, Autor AP, Hogg JC. Marginated pool of neutrophils in rabbit lungs. J Appl Physiol 1987; 63: 1806-1815.

40 Imanaka H, Shimaoka M, Matsuura N, Nishimura M, Ohta N, Kiyono H. Ventilator-induced lung injury is associated with neutrophil infiltration, macrophage activation, and TGF- $\beta 1$ mRNA upregulation in rat lungs. Anesth Analg 2001; 92: 428-436.

41 Reutershan J, Ley K. Bench-to-bedside review: acute respiratory distress syndrome - how neutrophils migrate into the lung. Crit Care 2004; 8: 453-461.

42 Choudhury S, Wilson MR, Goddard ME, O'Dea KP, Takata M. Mechanisms of early pulmonary neutrophil sequestration in ventilator-induced lung injury in mice. Am J Physiol Lung Cell Mol Physiol 2004; 287: L902-L910.

43 Kirchner EA, Mols G, Hermle G, et al. Reduced activation of immunomodulatory transcription factors during positive end-expiratory pressure adjustment based on volume-dependent compliance in isolated perfused rabbit lungs. Br J Anaesth 2005; 94: 530-535.

44 Toth I, Leiner T, Mikor A, Szakmany T, Bogar L, Molnar Z. Hemodynamic and respiratory changes during lung recruitment and descending optimal positive endexpiratory pressure titration in patients with acute respiratory distress syndrome. Crit Care Med 2007; 35: 787-793.

45 Girgis K, Hamed H, Khater Y, Kacmarek RM. A decremental PEEP trial identifies the PEEP level that maintains oxygenation after lung recruitment. Respir Care 2006; 51: 1132-1139.

46 Reis Miranda D, Gommers D, Struijs A, et al. Ventilation according to the open lung concept attenuates pulmonary inflammatory response in cardiac surgery. Eur J Cardiothorac Surg 2005; 28: 889-895.

47 Parsons PE, Eisner MD, Thompson BT, et al. Lower tidal volume ventilation and plasma cytokine markers of inflammation in patients with acute lung injury. Crit Care Med 2005; 33: 1-6; discussion 230-232.

48 Tamura DY, Moore EE, Partrick DA, Johnson JL, Offner PJ, Silliman CC. Acute hypoxemia in humans enhances the neutrophil inflammatory response. Shock 2002; 17: 269-273.

49 Haitsma JJ, Uhlig S, Verbrugge SJ, Goggel R, Poelma DL, Lachmann B. Injurious ventilation strategies cause systemic release of IL-6 and MIP-2 in rats in vivo. Clin Physiol Funct Imaging 2003; 23: 349-353.

50 Bregeon F, Roch A, Delpierre S, et al. Conventional mechanical ventilation of healthy lungs induced proinflammatory cytokine gene transcription. Respir Physiol Neurobiol 2002; 132: 191-203.
51 Schutte H, Lohmeyer J, Rosseau S, et al. Bronchoalveolar and systemic cytokine profiles in patients with ARDS, severe pneumonia and cardiogenic pulmonary oedema. Eur Respir J 1996; 9: 1858-1867.

52 Hippenstiel S, Witzenrath M, Schmeck B, et al. Adrenomedullin reduces endothelial hyperpermeability. Circ Res 2002; 91: 618-625.

53 Takao Y, Mikawa K, Nishina K, Obara H. Attenuation of acute lung injury with propofol in endotoxemia. Anesth Analg 2005; 100: 810-816.

54 Amigues L, Klouche K, Massanet P, et al. Sirolimusassociated acute respiratory distress syndrome in a renal transplant recipient. Transplant Proc 2005; 37: 2830-2831.

55 Montero AJ, McCarthy JJ, Chen G, Rice L. Acute respiratory distress syndrome after rituximab infusion. Int J Hematol 2005; 82: 324-326.

56 Lutz W, Stetkiewicz J. High mobility group box 1 protein as a late-acting mediator of acute lung inflammation. Int J Occup Med Environ Health 2004; 17: 245-254.

57 Baumgarten G, Knuefermann P, Wrigge H, et al. Role of Toll-like receptor 4 for the pathogenesis of acute lung injury in Gram-negative sepsis. Eur J Anaesthesiol 2006; 23: 1041-1048

58 Yeh CC, Kao SJ, Lin CC, Wang SD, Liu CJ, Kao ST. The immunomodulation of endotoxin-induced acute lung injury by hesperidin in vivo and in vitro. Life Sci 2007; 80: 1821-1831.

59 Pespeni M, Mackersie RC, Lee H, et al. Serum levels of Hsp60 correlate with the development of acute lung injury after trauma. J Surg Res 2005; 126: 41-47.

60 Liszewski MK, Atkinson JP. Novel complement inhibitors. Expert Opin Investig Drugs 1998; 7: 323-331.

61 Bengsch S, Boos KS, Nagel D, Seidel D, Inthorn D. Extracorporeal plasma treatment for the removal of endotoxin in patients with sepsis: clinical results of a pilot study. Shock 2005; 23: 494-500.

62 Haase M, Silvester W, Uchino S, et al. A pilot study of high-adsorption hemofiltration in human septic shock. Int J Artif Organs 2007; 30: 108-117.

63 Morgera S, Klonower D, Rocktaschel J, et al. TNF- $\alpha$ elimination with high cut-off haemofilters: a feasible clinical modality for septic patients? Nephrol Dial Transplant 2003; 18: 1361-1369.

64 Uchino S, Bellomo R, Morimatsu H, et al. Cytokine dialysis: an ex vivo study. Asaio J 2002; 48: 650-653.

65 Toft P, Brix-Christensen V, Baech J, et al. Effect of hemodiafiltration and sepsis on chemotaxis of granulocytes and the release of IL-8 and IL-10. Acta Anaesthesiol Scand 2002; 46: 138-144.

66 Braun N, Rosenfeld S, Giolai M, et al. Effect of continuous hemodiafiltration on IL-6, TNF- $\alpha, \mathrm{C} 3 \mathrm{a}$, and TCC in patients with SIRS/septic shock using two different membranes. Contrib Nephrol 1995; 116: 89-98.

67 Bellomo R, Tipping P, Boyce N. Interleukin-6 and interleukin-8 extraction during continuous venovenous hemodiafiltration in septic acute renal failure. Ren Fail 1995; 17: 457-466.

68 Bellomo R, Tipping P, Boyce N. Continuous veno-venous hemofiltration with dialysis removes cytokines from the circulation of septic patients. Crit Care Med 1993; 21: 522-526. 
69 Wang L, Bastarache JA, Wickersham N, Fang X, Matthay MA, Ware LB. Novel role of the human alveolar epithelium in regulating intra-alveolar coagulation. Am J Respir Cell Mol Biol 2007; 36: 497-503.

70 Maybauer MO, Maybauer DM, Fraser JF, et al. Recombinant human activated protein $\mathrm{C}$ improves pulmonary function in ovine acute lung injury resulting from smoke inhalation and sepsis. Crit Care Med 2006; 34: 2432-2438.

71 Ware LB, Bastarache JA, Wang L. Coagulation and fibrinolysis in human acute lung injury - new therapeutic targets? Keio J Med 2005; 54: 142-149.

72 Jesmin S, Gando S, Matsuda N, et al. Temporal changes in pulmonary expression of key procoagulant molecules in rabbits with endotoxin-induced acute lung injury: elevated expression levels of protease-activated receptors. Thromb Haemost 2004; 92: 966-979.

73 He XL, Liu Z, Xia SY. Vascular endothelial injuries and changes of blood coagulation and fibrinolysis indexes in patients with acute respiratory distress syndrome. Chin Med Sci J 2004; 19: 252-256.

74 Prabhakaran P, Ware LB, White KE, Cross MT, Matthay MA, Olman MA. Elevated levels of plasminogen activator inhibitor-1 in pulmonary edema fluid are associated with mortality in acute lung injury. Am J Physiol Lung Cell Mol Physiol 2003; 285: L20-L28.

75 Laterre PF, Wittebole X, Dhainaut JF. Anticoagulant therapy in acute lung injury. Crit Care Med 2003; 31: Suppl. 4, S329-S336.

76 Welty-Wolf KE, Carraway MS, Idell S, Ortel TL, Ezban M, Piantadosi CA. Tissue factor in experimental acute lung injury. Semin Hematol 2001; 38: Suppl. 4, S35-S38.

77 Kinasewitz GT, Yan SB, Basson B, et al. Universal changes in biomarkers of coagulation and inflammation occur in patients with severe sepsis, regardless of causative microorganism [ISRCTN74215569]. Crit Care 2004; 8: R82-R90.

78 Russell JA. Genetics of coagulation factors in acute lung injury. Crit Care Med 2003; 31: Suppl. 4, S243-S247.

79 Bryant AE. Biology and pathogenesis of thrombosis and procoagulant activity in invasive infections caused by group A streptococci and Clostridium perfringens. Clin Microbiol Rev 2003; 16: 451-462.

80 Schiffer ER, Reber G, De Moerloose P, Morel DR. Evaluation of unfractionated heparin and recombinant hirudin on survival in a sustained ovine endotoxin shock model. Crit Care Med 2002; 30: 2689-2699.

81 Idell S. Adult respiratory distress syndrome: do selective anticoagulants help? Am J Respir Med 2002; 1: 383-391.

82 Opal SM. Clinical impact of novel anticoagulation strategies in sepsis. Curr Opin Crit Care 2001; 7: 347-353.

$83 \mathrm{Xu} \mathrm{H}$, Ploplis VA, Castellino FJ. A coagulation factor VII deficiency protects against acute inflammatory responses in mice. J Pathol 2006; 210: 488-496.

84 Schultz MJ, Haitsma JJ, Zhang H, Slutsky AS. Pulmonary coagulopathy as a new target in therapeutic studies of acute lung injury or pneumonia - a review. Crit Care Med 2006; 34: 871-877.

85 Robriquet L, Collet F, Tournoys A, et al. Intravenous administration of activated protein $\mathrm{C}$ in Pseudomonasinduced lung injury: impact on lung fluid balance and the inflammatory response. Respir Res 2006; 7: 41.
86 Kipnis E, Guery BP, Tournoys A, et al. Massive alveolar thrombin activation in Pseudomonas aeruginosa-induced acute lung injury. Shock 2004; 21: 444-451.

87 Bastarache J, Wang L, Geiser T, et al. The alveolar epithelium can initiate the extrinsic coagulation cascade through expression of tissue factor. Thorax 2007; 62: 608-616.

88 Pittet JF, Mackersie RC, Martin TR, Matthay MA. Biological markers of acute lung injury: prognostic and pathogenetic significance. Am J Respir Crit Care Med 1997; 155: 1187-1205.

89 Chesnutt AN, Matthay MA, Tibayan FA, Clark JG. Early detection of type III procollagen peptide in acute lung injury. Pathogenetic and prognostic significance. Am J Respir Crit Care Med 1997; 156: 840-845.

90 Chapman HA, Yang XL, Sailor LZ, Sugarbaker DJ. Developmental expression of plasminogen activator inhibitor type 1 by human alveolar macrophages. Possible role in lung injury. J Immunol 1990; 145: 3398-3405.

91 Guzik TJ, Channon KM. Measurement of vascular reactive oxygen species production by chemiluminescence. Methods Mol Med 2005; 108: 73-89.

92 Tarpey MM, Wink DA, Grisham MB. Methods for detection of reactive metabolites of oxygen and nitrogen: in vitro and in vivo considerations. Am J Physiol Regul Integr Comp Physiol 2004; 286: R431-R444.

93 Takenaka K, Nishimura Y, Nishiuma T, et al. Ventilatorinduced lung injury is reduced in transgenic mice that overexpress endothelial nitric oxide synthase. Am J Physiol Lung Cell Mol Physiol 2006; 290: L1078-L1086.

94 Choi WI, Quinn DA, Park KM, et al. Systemic microvascular leak in an in vivo rat model of ventilator-induced lung injury. Am J Respir Crit Care Med 2003; 167: 1627-1632.

95 Frank JA, Wray CM, McAuley DF, Schwendener R, Matthay MA. Alveolar macrophages contribute to alveolar barrier dysfunction in ventilator-induced lung injury. Am J Physiol Lung Cell Mol Physiol 2006; 291: L1191-L1198.

96 Zapol WM. Minidose inhaled nitric oxide: less is better. Intensive Care Med 1993; 19: 433-434.

97 Gerlach H, Pappert D, Lewandowski K, Rossaint R, Falke KJ. Long-term inhalation with evaluated low doses of nitric oxide for selective improvement of oxygenation in patients with adult respiratory distress syndrome. Intensive Care Med 1993; 19: 443-449.

98 McQuaid KE, Keenan AK. Endothelial barrier dysfunction and oxidative stress: roles for nitric oxide? Exp Physiol 1997; 82: 369-376.

99 Oeckler RA, Wolin MS. New concepts in vascular nitric oxide signaling. Curr Atheroscler Rep 2000; 2: 437-444.

100 Chapman KE, Sinclair SE, Zhuang D, Hassid A, Desai LP, Waters CM. Cyclic mechanical strain increases reactive oxygen species production in pulmonary epithelial cells. Am J Physiol Lung Cell Mol Physiol 2005; 289: L834-L841.

101 Oeckler RA, Kaminski PM, Wolin MS. Stretch enhances contraction of bovine coronary arteries via an $\mathrm{NAD}(\mathrm{P}) \mathrm{H}$ oxidase-mediated activation of the extracellular signalregulated kinase mitogen-activated protein kinase cascade. Circ Res 2003; 92: 23-31. 
102 Usatyuk PV, Vepa S, Watkins T, He D, Parinandi NL, Natarajan V. Redox regulation of reactive oxygen speciesinduced p38 MAP kinase activation and barrier dysfunction in lung microvascular endothelial cells. Antioxid Redox Signal 2003; 5: 723-730.

103 Wang W, Suzuki Y, Tanigaki T, Rank DR, Raffin TA. Effect of the NADPH oxidase inhibitor apocynin on septic lung injury in guinea pigs. Am J Respir Crit Care Med 1994; 150: 1449-1452.

104 Suzuki Y, Tanigaki T, Heimer D, et al. Polyethylene glycol-conjugated superoxide dismutase attenuates septic lung injury in guinea pigs. Am Rev Respir Dis 1992; 145: 388-393.

105 Baboolal HA, Ichinose F, Ullrich R, Kawai N, Bloch KD, Zapol WM. Reactive oxygen species scavengers attenuate endotoxin-induced impairment of hypoxic pulmonary vasoconstriction in mice. Anesthesiology 2002; 97: 1227-1233.

106 Kjaeve J, Ingebrigtsen T, Naess L, Bjertnaes L, Vaage J. Methylprednisolone attenuates airway and vascular responses induced by reactive oxygen species in isolated, plasma-perfused rat lungs. Free Radic Res 1996; 25: 407-414.

107 Rahman I, Kelly F. Biomarkers in breath condensate: a promising new non-invasive technique in free radical research. Free Radic Res 2003; 37: 1253-1266.

108 Dunican AL, Leuenroth SJ, Grutkoski P, Ayala A, Simms $\mathrm{HH}$. TNF $\alpha$-induced suppression of PMN apoptosis is mediated through interleukin-8 production. Shock 2000; 14: 284-288; discussion 288-289.

109 Petrache I, Verin AD, Crow MT, Birukova A, Liu F, Garcia JG. Differential effect of MLC kinase in TNF- $\alpha-$ induced endothelial cell apoptosis and barrier dysfunction. Am J Physiol Lung Cell Mol Physiol 2001; 280: L1168-L1178.

110 Yoshikawa S, King JA, Lausch RN, Penton AM, Eyal FG, Parker JC. Acute ventilator-induced vascular permeability and cytokine responses in isolated and in situ mouse lungs. J Appl Physiol 2004; 97: 2190-2199.

111 Fujita M, Kuwano K, Kunitake R, et al. Endothelial cell apoptosis in lipopolysaccharide-induced lung injury in mice. Int Arch Allergy Immunol 1998; 117: 202-208.

112 Krunkosky TM, Fischer BM, Akley NJ, Adler KB. Tumor necrosis factor $\alpha$ (TNF $\alpha$ )-induced ICAM-1 surface expression in airway epithelial cells in vitro: possible signal transduction mechanisms. Ann NY Acad Sci 1996; 796: 30-37.

113 Husain KD, Stromberg PE, Javadi P, et al. Bcl-2 inhibits gut epithelial apoptosis induced by acute lung injury in mice but has no effect on survival. Shock 2003; 20: 437-443.

114 Alvira CM, Abate A, Yang G, Dennery PA, Rabinovitch M. Nuclear factor- $\kappa \mathrm{B}$ activation in neonatal mouse lung protects against lipopolysaccharide-induced inflammation. Am J Respir Crit Care Med 2007; 175: 805-815.

115 de Souza PM, Lindsay MA. Apoptosis as a therapeutic target for the treatment of lung disease. Curr Opin Pharmacol 2005; 5: 232-237.

116 Genovese T, Mazzon E, Di Paola R, et al. Inhibitors of poly(ADP-ribose) polymerase modulate signal transduction pathways and the development of bleomycin-induced lung injury. J Pharmacol Exp Ther 2005; 313: 529-538.

117 Jin Y, Choi AM. Cytoprotection of heme oxygenase-1/ carbon monoxide in lung injury. Proc Am Thorac Soc 2005; 2: 232-235.

118 St Croix CM, Leelavaninchkul K, Watkins SC, Kagan VE, Pitt BR. Nitric oxide and zinc homeostasis in acute lung injury. Proc Am Thorac Soc 2005; 2: 236-242.

119 Standiford TJ, Keshamouni VG, Reddy RC. Peroxisome proliferator-activated receptor- $\gamma$ as a regulator of lung inflammation and repair. Proc Am Thorac Soc 2005; 2: 226-231.

120 Suzuki T, Moraes TJ, Vachon E, et al. Proteinase-activated receptor-1 mediates elastase-induced apoptosis of human lung epithelial cells. Am J Respir Cell Mol Biol 2005; 33: 231-247.

121 Bingisser R, Stey C, Weller M, Groscurth P, Russi E, Frei K. Apoptosis in human alveolar macrophages is induced by endotoxin and is modulated by cytokines. Am J Respir Cell Mol Biol 1996; 15: 64-70.

122 Goodman ER, Stricker P, Velavicius M, et al. Role of granulocyte-macrophage colony-stimulating factor and its receptor in the genesis of acute respiratory distress syndrome through an effect on neutrophil apoptosis. Arch Surg 1999; 134: 1049-1054.

123 Matute-Bello G, Liles WC, Radella F 2nd, et al, Modulation of neutrophil apoptosis by granulocyte colony-stimulating factor and granulocyte/macrophage colony-stimulating factor during the course of acute respiratory distress syndrome. Crit Care Med 2000; 28: 1-7.

124 Thickett DR, Armstrong L, Christie SJ, Millar AB. Vascular endothelial growth factor may contribute to increased vascular permeability in acute respiratory distress syndrome. Am J Respir Crit Care Med 2001; 164 1601-1605.

125 Gillette MA, Hess DR. Ventilator-induced lung injury and the evolution of lung-protective strategies in acute respiratory distress syndrome. Respir Care 2001; 46: 130-148.

126 Dreyfuss D, Saumon G. Ventilator-induced lung injury: lessons from experimental studies. Am J Respir Crit Care Med 1998; 157: 294-323.

127 Dreyfuss D, Basset G, Soler P, Saumon G. Intermittent positive-pressure hyperventilation with high inflation pressures produces pulmonary microvascular injury in rats. Am Rev Respir Dis 1985; 132: 880-884.

128 Gajic O, Lee J, Doerr CH, Berrios JC, Myers JL, Hubmayr RD. Ventilator-induced cell wounding and repair in the intact lung. Am J Respir Crit Care Med 2003; 167: 1057-1063.

129 Vlahakis NE, Hubmayr RD. Cellular stress failure in ventilator-injured lungs. Am J Respir Crit Care Med 2005; 171: 1328-1342.

130 Vlahakis NE, Schroeder MA, Pagano RE, Hubmayr RD. Deformation-induced lipid trafficking in alveolar epithelial cells. Am J Physiol Lung Cell Mol Physiol 2001; 280: L938-L946. 